\title{
Determinants of low birth weight in urban Pakistan
}

\author{
Naveed Zafar Janjua ${ }^{1,2, *}$, Elizabeth Delzell ${ }^{1}$, Rodney R Larson ${ }^{3}$, Sreelatha Meleth ${ }^{4}$, \\ Sibylle Kristensen ${ }^{1}$, Edmond Kabagambe ${ }^{1}$ and Nalini Sathiakumar ${ }^{1}$ \\ 'Department of Epidemiology, University of Alabama at Birmingham, 1665 University Blvd, RPHB 430, \\ Birmingham, AL 35294, USA: 'Department of Community Health Sciences, Aga Khan University, Karachi, \\ Pakistan: ${ }^{3}$ University of Utah, Salt Lake City, UT, USA: ${ }^{4}$ Department of Medicine, University of Alabama at \\ Birmingham, Birmingham, AL, USA
}

Submitted 16 December 2007: Accepted 2 May 2008: First published online 11 July 2008

\begin{abstract}
Objective: To identify determinants of low birth weight (LBW) in Karachi, Pakistan, including environmental exposures and nutritional status of the mother during pregnancy.

Design: Cross-sectional study.

Participants: Five hundred and forty mother-infant pairs. We interviewed mothers about obstetric history, diet and exposure to $\mathrm{Pb}$. We measured birth weight and blood lead level (BLL). We performed multiple log binomial regression analysis to identify factors related to LBW.

Results: Of 540 infants, $100(18 \cdot 5 \%)$ weighed $\leq 2.5 \mathrm{~kg}$. Umbilical cord BLL was not significantly associated with LBW. Maternal poor self-rated health (adjusted prevalence ratio $(\operatorname{adjPR})=1 \cdot 83 ; 95 \%$ CI $1 \cdot 09,3 \cdot 07)$ and none or one prenatal visit $(\operatorname{adjPR}=2 \cdot 18 ; 95 \%$ CI $1 \cdot 39,3 \cdot 43)$ were associated with LBW. A statistically significant interaction between mothers' mid upper-arm circumference (MUAC) and dietary vitamin $\mathrm{C}$ intake was noted. Compared with mothers with MUAC above the median and dietary vitamin $\mathrm{C}$ intake above the 3rd quartile $(>208.7 \mathrm{mg} / \mathrm{d})$, infants of mothers with MUAC less than or equal to the median and dietary vitamin $\mathrm{C}$ intake $>208 \cdot 7 \mathrm{mg} / \mathrm{d}(\operatorname{adjPR}=10 \cdot 80 ; 95 \% \mathrm{CI} 1 \cdot 46,79 \cdot 76)$, mothers with MUAC above the median and vitamin C intake $\leq 208.7 \mathrm{mg} / \mathrm{d}$ (adjPR $=10 \cdot 67$; $95 \%$ CI $1 \cdot 50,76 \cdot 02)$ and mothers with MUAC less than or equal to the median and vitamin $\mathrm{C}$ intake $\leq 208 \cdot 7 \mathrm{mg} / \mathrm{d}(\operatorname{adjPR}=13 \cdot 19 ; 95 \% \mathrm{CI} 1 \cdot 85,93 \cdot 79)$ more likely to give birth to an LBW infant.

Conclusions: In Pakistan, poor nutritional status and inadequate prenatal care were major determinants of LBW in this setting. Environmental factors including umbilical cord BLL were not significantly associated with LBW.
\end{abstract}

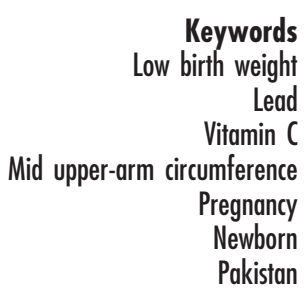

Low birth weight (LBW) remains a significant public health problem in many parts of the world and is associated with both short- and long-term adverse consequences. Globally, more than 20 million infants are born with LBW, about $15 \cdot 5 \%$ of all live births ${ }^{(1)}$. The prevalence of LBW is high in developing countries (18.5\%), with the highest prevalence in South Asia (27\%) including Pakistan $(19 \%)^{(1)}$. LBW infants have an increased risk of mortality during the neonatal period, infancy, childhood and during later during adulthood ${ }^{(2,3)}$.

Previous research has shown that birth weight is influenced by length of gestation, parity, prenatal care, education level of the mother and father, socio-economic status, maternal malnutrition, maternal smoking, environmental tobacco smoke (ETS), short stature of the mother, short birth intervals, maternal and fetal medical problems, as well as certain infections and exposure to environmental agents such as $\mathrm{Pb}$ and pesticides $^{(4-13)}$.

Risk factors for LBW in developing countries are different from those in developed countries. In the USA and European countries, the prevalence of LBW is relatively low (5-7\% of live births) and the main determinants of LBW are exposure to environmental toxins such as $\mathrm{Pb}$, ambient air pollution, lack of prenatal care and low socioeconomic status. In contrast, most developing countries have a high prevalence of both LBW and maternal malnutrition and dietary deficiencies ${ }^{(14)}$. In addition, developing countries have high levels of rising urban environmental pollutants such as $\mathrm{Pb}$. Thus, there is a need to evaluate the relationship between $\mathrm{Pb}$ exposure and LBW in regions with high prevalence of other potential risk factors for LBW. The present study examined the determinants of LBW including $\mathrm{Pb}$ exposure, 
nutritional status and prenatal care during pregnancy in Karachi, Pakistan.

\section{Methods}

\section{Study setting}

The study was conducted in Karachi which is the largest city, the main port and the industrial and trade centre of Pakistan. Karachi has a population of more than 10 million, about $40 \%$ of whom live in squatter settlements. Karachi has potential for high $\mathrm{Pb}$ exposure from various environmental sources such as automobiles, industrial emissions and occupational exposures. The subjects for the present study were recruited at two tertiary-care hospitals located in the inner city, and comprised lowand middle-income patients from various parts of the city.

\section{Study design}

The present study was a cross-sectional study conducted between January and August 2005. Study subjects were mothers and their infants born during the study period.

\section{Study participants}

Eligible subjects were women who: (i) were willing to participate in the study; (ii) were residents of Karachi for at least 1 year; (iii) were admitted for delivery in one of the two study hospitals; and (iv) planned to deliver a singleton at term (37-42 weeks of gestation). Mothers were excluded if they had physician diagnoses of psychiatric morbidity, kidney or cardiac disease, history of repeated urinary tract infections, sickle cell anaemia, thyrotoxicosis, autoimmune diseases such as Crohn's or coeliac disease, drug dependence, steroid intake during pregnancy, antepartum haemorrhage, placental abnormalities such as abruptio placentae, pre-eclampsia or a fetus with congenital anomalies.

\section{Subject selection}

We randomly selected ten mothers each day who registered for delivery at the study hospitals. We invited selected mothers for eligibility screening using medical records. Those found eligible at this stage were invited for participation in the study and written consent was obtained.

\section{Exposure assessments}

We used maternal interview, medical record review and maternal anthropometric examination, and umbilical cord blood for assessment of potential risk factors.

We used a pre-tested Urdu translated questionnaire to collect information. Registered nurses conducted interviews after training in interviewing and field procedures. Study procedures were pilot-tested before the start of data collection. Maternal interview and measurements were conducted both before and after delivery depending on the mother's condition.
The questionnaire elicited information on sociodemographic factors, obstetric history, diet during pregnancy and sources of $\mathrm{Pb}$ exposure. Sociodemographic factors included maternal age, education, occupation, husband's education and occupation, household income and possession of household assets. Socio-economic status was assessed using income and a wealth index based on household possessions with proportionate weighting.

The questionnaire also elicited information on current and past obstetric history including parity, pre-pregnancy weight, prenatal care (number, time of each visit and services provided), history of vaginal discharge, feeling of depressive symptoms (measured on a scale of $1-5$, from none to extreme feeling), overall health status (measured on a scale of excellent, very good, good, fair and poor), hours of rest during day and night, total hours spent in the kitchen, perception of work load during pregnancy, potential exposure to indoor pollution (measured by type of kitchen), smoking during pregnancy, exposure to ETS at home or work, use of DDT (dichlorodiphenyltrichloroethane), mosquito coils and rodenticides, anaemia during pregnancy, history of acute upper respiratory tract infection, fever, physician diagnosed high blood pressure, gestational diabetes, and use of calcium/iron/ vitamin C supplements with the quantity, duration and brand name during pregnancy.

We assessed dietary intake of $\mathrm{Ca}$, Fe and vitamin $\mathrm{C}$ during current pregnancy using an FFQ adapted from a previous study of dietary intake during pregnancy in Karachi $^{(15)}$. The FFQ elicited information on the intake of foods in the most recent month, including the frequency per week and the quantity according to portion size. To help in recall, pictures and models of standard portion sizes applicable in the local settings were used. Total Ca intake was estimated from questionnaire data on supplements and diet. For supplements, the quantity of Ca was abstracted using manufacturer information provided in a drug index and then the quantity from each supplement taken each day was summed to obtain daily Ca intake from supplements. Dietary Ca intake was derived from the quantity of $\mathrm{Ca}$ contained in each food item on the FFQ. Ca content estimates were obtained from Pakistani food tables. If a food was not available in the Pakistani food table, Ca content was derived from Indian or US food tables. The amount of Ca consumed was computed by multiplying Ca contained in a serving of food by the number of servings of food consumed each day. Total Ca intake per day was the sum of $\mathrm{Ca}$ from diet and supplements. The same approach was used to compute elemental $\mathrm{Fe}$ and vitamin $\mathrm{C}$ intake from supplements, diet and daily total intake.

Maternal weight, height, mid upper-arm circumference (MUAC) and biceps and triceps skinfold thickness were measured after delivery. Three measurements of MUAC, biceps and triceps skinfolds were taken on the nondominant arm. MUAC and the biceps skinfold thickness 
(BSFT) have been shown to predict pre-pregnancy nutritional status, as these indices change very little during pregnancy ${ }^{(16)}$. Medical records were reviewed for gestational age measured by ultrasound, high blood pressure during pregnancy, glucose intolerance and gestational diabetes.

$\mathrm{Pb}$ levels were tested in umbilical cord blood. At delivery, an umbilical cord blood sample was collected into a trace metal-free BD Vacutainer ${ }^{\mathrm{TM}}$ sterile glass tube containing $\mathrm{Na}_{2}$ EDTA. The analysis for $\mathrm{Pb}$ level was performed at the laboratory of the Pakistan Institute of Scientific and Industrial Research (PCSIR) in Karachi, using graphite furnace atomic absorption spectrophotometry. PCSIR has been participating in the Centers for Disease Control and Prevention (CDC) Blood Lead Laboratory Reference System (BLLRS). For the present study, PCSIR tested BLLRS bovine blood. The intra-class correlation coefficient was 0.999 , and the mean (SD) of PCSIR was $29 \cdot 7(19 \cdot 4) \mu \mathrm{g} / \mathrm{dl} v$. the mean (SD) CDC target value of $30 \cdot 40(19 \cdot 17) \mu \mathrm{g} / \mathrm{dl}$.

\section{Outcome assessment}

The outcome of interest was LBW. LBW was defined as infant weight $\leq 2.5 \mathrm{~kg}$. Infant anthropometrics were measured within $12 \mathrm{~h}$ of birth. Birth weight was measured using an infant pan scale, length using a flat board, and head and chest circumferences were measured using a non-stretchable tape.

\section{Sample size}

Sample size estimation was based on the relationship of umbilical cord blood lead level (BLL) and LBW. We assumed that about $80 \%$ of women will have BLL $\geq 10$ $\mu \mathrm{g} / \mathrm{dl}$ as in a previous study on children ${ }^{(17)}$ and umbilical cord BLL will be $75-90 \%$ of maternal levels ${ }^{(18)}$. By assuming umbilical cord BLL to be $80 \%$ of maternal levels, $64 \cdot 2 \%$ of newborns were expected to have umbilical cord BLL $\geq 10 \mu \mathrm{g} / \mathrm{dl}$. Thus the sample size for examining the relationship between BLL and LBW was based on the assumption that $64 \%$ of normal-weight infants would have BLL $\geq 10 \mu \mathrm{g} / \mathrm{dl}$. With $5 \%$ significance and $80 \%$ power and assuming a 1:3 ratio of normal and LBW babies, to detect an odds ratio of $2 \cdot 0$ and with $10 \%$ non-response rate we would require a sample size of 533 newborns. Thus, we enrolled 540 mothers and infants.

\section{Data analysis}

Data were double-entered into Epi Info ${ }^{\mathrm{TM}} 2002$ software (CDC, Atlanta, GA, USA) and analysed using the Statistical Analysis Systems statistical software package version $9 \cdot 1 \cdot 3$ (SAS Institute, Cary, NC, USA).

We computed proportions for categorical variables and mean, standard deviation and median for continuous variables. We compared continuous variables using the $t$ test or ANOVA and categorical variables using the $\chi^{2}$ test.

We computed the prevalence of LBW for each category of a potential risk factor as the number of infants with birth weight $\leq 2.5 \mathrm{~kg}$ divided by the total number of normal-weight plus LBW infants in each category. We computed the crude prevalence ratio (PR) for exposure variables as the prevalence of LBW among those in the high-risk category divided by the prevalence in the unexposed or presumed to be low-risk category. We used a log binomial regression model to estimate the adjusted prevalence ratios (adjPR) using PROC GENMOD in SAS.

We categorized sociodemographic variables as follows: mother's age as $<20,20-30$ and $\geq 30$ years; mother's and father's education as $<5,6-12$ and $>12$ years; wealth index as low, medium and high; and monthly household income as below the median and greater than or equal to the median. MUAC and BSFT were dichotomized at the median. Vitamin C from diet was dichotomized into high (4th quartile) and low (1st-3rd quartile). Prenatal visits were categorized into $\geq 4,2-3$ and $\leq 1$. Time of first visit was categorized into during first 16 weeks, 17-28 weeks and $>28$ weeks of gestation. An index of prenatal care adequacy was created as follows: sufficient, $\geq 3$ visits and first visit before 16 weeks; fair, 2 visits or first visit between 17 and 24 weeks; and inadequate, no or 1 visit or first visit between 25 and 38 weeks. Overall health status was categorized into excellent, good, fair and poor.

Variables with $P<0.2$ in univariable analysis and umbilical cord BLL were considered for evaluation in multivariable analysis. We started with the most significant variable and added variables one by one while assessing their significance and change in effect estimate. Variables that were not significant or did not produce a change in effect estimate of $>10 \%$ were removed from the model. Variables significant at $P<0.05$ were kept in the final model. We tested interactions of variables in the model.

\section{Ethical approval}

The study was approved both by the Institutional Review Board of the University of Alabama at Birmingham and the Ethics Review Committee of the Aga Khan University in Karachi, Pakistan.

\section{Results}

\section{Study participants}

Of 807 mothers initially screened for eligibility, 565 were eligible. All subjects consented to participate in the study. Data on outcome or a major portion of the interview was missing for twenty-five participants. Thus 540 subjects were available for analysis, which was the planned target for enrolment (Fig. 1).

The gender distribution of infants was approximately equal (male, 54\%; female, 46\%). Mothers were relatively young with a median age of 25 years (Table 1 ). Fathers were more likely to have educational level greater than 12 th grade compared with mothers (14\%v. 6.5\%). Only 


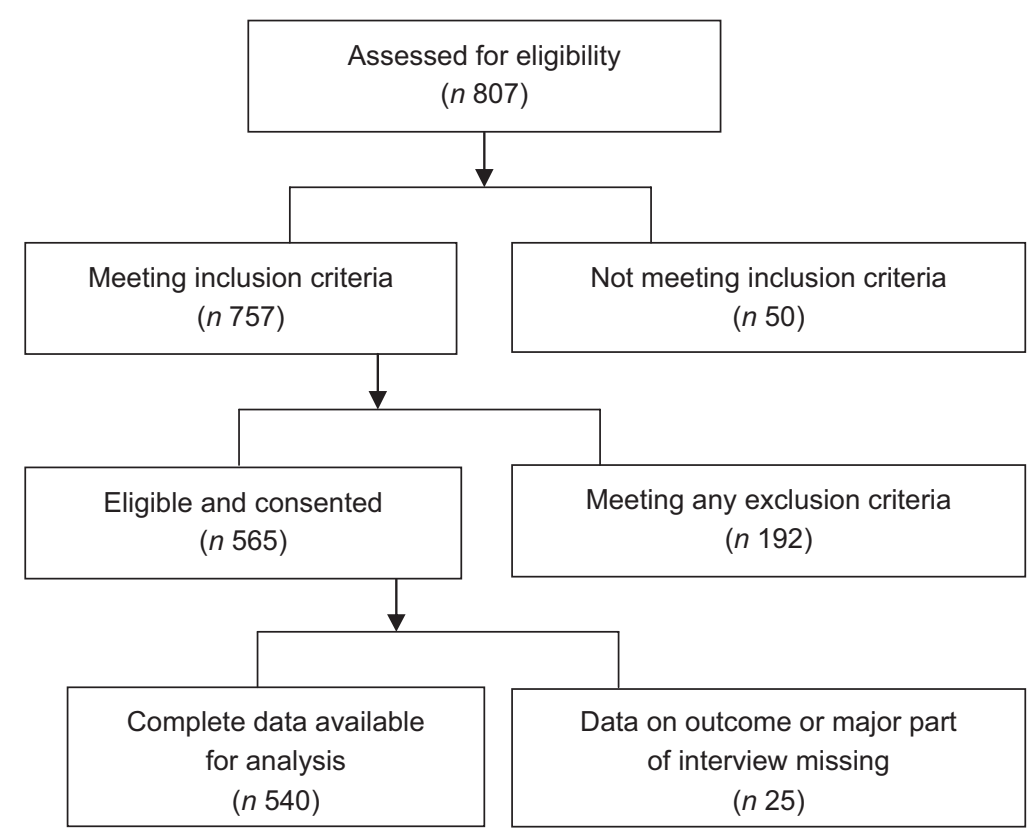

Fig. 1 Selection of participants in a study of umbilical cord blood lead levels and low birth weight in Karachi, Pakistan, 2005-2006

Table 1 Selected characteristics of 540 participants in a study of umbilical cord blood lead levels and low birth weight in Karachi, Pakistan, 2005-2006

\begin{tabular}{|c|c|c|}
\hline Variable & $n$ or Mean & $\%$ or SD \\
\hline \multicolumn{3}{|l|}{ Child characteristics } \\
\hline No. $(\%)$ of males & 289 & 54 \\
\hline Mean (SD) birth weight (kg) & $3 \cdot 0$ & 0.5 \\
\hline Mean (SD) crown-heel length (cm) & $50 \cdot 3$ & $2 \cdot 6$ \\
\hline Mean (SD) head circumference $(\mathrm{cm})$ & $34 \cdot 6$ & $1 \cdot 9$ \\
\hline Geometric mean (SD) of cord BLL $(\mu \mathrm{g} / \mathrm{dl})$ & $9 \cdot 6$ & $1 \cdot 6$ \\
\hline Arithmetic mean $(\mathrm{SD})$ of cord BLL ( $\mu \mathrm{g} / \mathrm{dl})$ & $10 \cdot 8$ & $0 \cdot 2$ \\
\hline \multicolumn{3}{|l|}{ Parent characteristics } \\
\hline Mean (SD) age of mother at delivery (years) & $25 \cdot 3$ & $4 \cdot 6$ \\
\hline Mean (SD) years of mother's schooling & $7 \cdot 4$ & $4 \cdot 4$ \\
\hline Mean (SD) years of fathers' schooling & $8 \cdot 5$ & $4 \cdot 4$ \\
\hline No. $(\%)$ of mothers employed & 12 & $2 \cdot 2$ \\
\hline No. $(\%)$ of fathers manual and minimal skilled labourers & 320 & 59 \\
\hline No. (\%) of households with income above Rs. 7000 & 251 & 46 \\
\hline No. (\%) of households owning a car & 23 & 4 \\
\hline No. (\%) of mothers of Urdu (Mohajir)* ethnicity & 368 & 68 \\
\hline Mean (SD) parity & $1 \cdot 2$ & $1 \cdot 3$ \\
\hline Mean (SD) maternal BMI $\left(\mathrm{kg} / \mathrm{m}^{2}\right)$ & $24 \cdot 6$ & $4 \cdot 4$ \\
\hline Mean (SD) maternal MUAC (cm) & $29 \cdot 0$ & $4 \cdot 0$ \\
\hline Mean (SD) maternal BSFT (mm) & $9 \cdot 7$ & $3 \cdot 5$ \\
\hline No. $(\%)$ of mothers anaemic $(\mathrm{Hb}<11 \mathrm{~g} / \mathrm{dl})+$ & 307 & 70 \\
\hline Mean (SD) total Ca intake during pregnancy & $974 \cdot 0$ & $370 \cdot 9$ \\
\hline Mean (SD) dietary Ca intake during pregnancy & $747 \cdot 1$ & $298 \cdot 2$ \\
\hline No. (\%) using Ca supplements during pregnancy & 376 & 70 \\
\hline Mean (SD) Ca intake from supplements among supplement usersł & $325 \cdot 7$ & $147 \cdot 3$ \\
\hline Mean (SD) total vitamin C intake during pregnancy & $801 \cdot 5$ & $697 \cdot 5$ \\
\hline Mean (SD) dietary vitamin C intake during pregnancył & $286 \cdot 5$ & $238 \cdot 6$ \\
\hline No. (\%) using vitamin $\mathrm{C}$ supplements during pregnancy & 406 & 75 \\
\hline Mean (SD) vitamin C intake from supplements among supplement usersł & $685 \cdot 0$ & $649 \cdot 0$ \\
\hline Mean (SD) total Fe intake during pregnancy & $70 \cdot 0$ & $83 \cdot 1$ \\
\hline Mean (SD) dietary Fe intake during pregnancył & $23 \cdot 1$ & $9 \cdot 3$ \\
\hline No. (\%) using Fe supplements during pregnancy & 203 & 38 \\
\hline Mean (SD) Fe intake from supplements among supplement usersł & $124 \cdot 8$ & $90 \cdot 8$ \\
\hline
\end{tabular}

BLL, blood lead level; MUAC, mid upper-arm circumference; BSFT, biceps skinfold thickness.

*The Mohajirs are a group of people who migrated from parts of India not included in Pakistan at the time of creation of Pakistan, and they mostly speak Urdu.

tData not available for all subjects.

‡Daily intake measured in $\mathrm{mg}$. 
$2 \%$ of mothers were employed. About $59 \%$ of fathers were manual or skilled labourers. Almost all homes (98\%) used natural gas as cooking fuel. The median monthly household income was Rs. 7000 (US\$ 117). About $4 \%$ of households owned a car. The mean maternal BMI was $24.5 \mathrm{~kg} / \mathrm{m}^{2}$, while $4 \%$ had BMI below $18.5 \mathrm{~kg} / \mathrm{m}^{2}$ and $12 \%$ had $\mathrm{BMI} \geq 30.0 \mathrm{~kg} / \mathrm{m}^{2}$. The mean daily $\mathrm{Ca}$, vitamin $\mathrm{C}$ and $\mathrm{Fe}$ intake was $974.0 \mathrm{mg}, 801.5 \mathrm{mg}$ and $70.0 \mathrm{mg}$, respectively (Table 1 ).

The median birth weight was $3.0 \mathrm{~kg}$, and median head circumference was $34.5 \mathrm{~cm}$. Of 540 infants, 100 (18.5\%) infants were born with weight $\leq 2.5 \mathrm{~kg}$. In the univariable analyses, factors statistically significantly associated with LBW included MUAC, BSFT, dietary vitamin C intake, cooking frequency, hours of rest during the third trimester, number of prenatal visits, feeling of depressive symptoms and perception about health status (Table 2).

Multivariable log binomial regression modelling indicated that perceived health status, number of prenatal visits, parity and interaction of MUAC and dietary vitamin C intake during pregnancy were significantly associated with LBW. High umbilical cord BLL was not associated with LBW. Mothers who perceived that their health status was poor were more likely to give birth to an LBW infant than mothers who reported good health status (adjPR $=$ 1.83; $95 \%$ CI $1 \cdot 09,3 \cdot 07)$. Mothers who had one or no prenatal care visits during pregnancy were twice as likely to give birth to an LBW infant than mothers who had four or more visits $(\operatorname{adjPR}=2 \cdot 18 ; 95 \%$ CI $1 \cdot 39,3 \cdot 43)$. There was a significant interaction of MUAC and dietary vitamin C intake. Those mothers who had MUAC $\leq 28.9 \mathrm{~cm}$ (equal to or below median) and vitamin $\mathrm{C}$ intake $>208.7 \mathrm{mg} / \mathrm{d}$ (4th quartile) were eleven times more likely to give birth to an LBW infant (adjPR $=10 \cdot 80 ; 95 \% \mathrm{CI}$ $1 \cdot 46,79 \cdot 76$ ). Mothers who had MUAC $>28.9 \mathrm{~cm}$ and vitamin C intake $\leq 208.7 \mathrm{mg} / \mathrm{d}$ were also eleven times more likely to give birth to an $\mathrm{LBW}$ infant (adjPR $=10 \cdot 67$; $95 \%$ CI $1 \cdot 50,76 \cdot 02)$, and those who had MUAC $\leq 28 \cdot 9 \mathrm{~cm}$ and vitamin $C$ intake $\leq 208.7 \mathrm{mg} / \mathrm{d}$ were thirteen times more likely to give birth to an $\mathrm{LBW}$ infant (adjPR $=13 \cdot 19$; $95 \%$ CI $1.85,93 \cdot 79$ ), as compared with those who had MUAC $>28.9 \mathrm{~cm}$ and vitamin C intake $>208.7 \mathrm{mg} / \mathrm{d}$. Women who were pregnant for the first time or had given birth five or more times were more likely to give birth to an $\mathrm{LBW}$ infant (adjPR $=1 \cdot 53 ; 95 \%$ CI 1.08, 3.43). We also developed a model with maternal BSFT replacing maternal MUAC and the results were similar (Table 3).

\section{Discussion}

In the present study of mother-infant pairs recruited from tertiary-care hospitals of Karachi, low vitamin C intake and MUAC below the median, poor perceived health status, and low prenatal care were associated with LBW. These results suggest that nutritional factors, prenatal care and perceived health status are important determinants of birth weight in a population where nutritional deficiencies are common and prenatal care is not adequate. Thus, improving overall nutritional status and access to prenatal care will be critical steps in reducing LBW.

Our study found that nutritional status of the mothers modified the effect of dietary vitamin $\mathrm{C}$ intake during pregnancy on LBW. Mothers who had low dietary intake of vitamin $\mathrm{C}$ and poor nutritional status as measured by below-median MUAC and BSFT were more likely to give birth to an LBW infant. Many studies from other parts of the world have reported the association of indices of maternal nutritional status (MUAC, BSFT, weight, BMI) with infant birth weight ${ }^{(19-21)}$. For example, a recent study in Zimbabwe reported that maternal MUAC was strongly related with $\mathrm{LBW}^{(20)}$; another in Sao Paulo, Brazil, reported an association between LBW and MUAC ${ }^{(19)}$.

Previous studies have also reported the association of low vitamin C intake during pregnancy with LBW. In a follow-up study of women in rural India, intake of green leafy vegetables and fruits - both rich sources of vitamin $\mathrm{C}$ - was significantly associated with higher birth weight. Investigators reported that the effect was strongest in lighter and thinner women ${ }^{(22)}$. Another study in the UK also found a positive association of dietary vitamin C intake during pregnancy and birth weight ${ }^{(23)}$. A Korean study reported that higher serum vitamin $\mathrm{C}$ and vitamin $\mathrm{E}$ during pregnancy are associated with higher birth weight ${ }^{(24)}$. Recent evidence indicates a role of oxidative stress in the pathophysiology of $\mathrm{LBW}^{(25,26)}$. Vitamins C and $\mathrm{E}$ are antioxidants and counteract oxidative stress. Our findings of an association of vitamin $\mathrm{C}$ and birth weight are consistent with the aforementioned studies. Taken together, both our results and these previous findings have important public health implications for providing vitamin $\mathrm{C}$ during pregnancy. Our results also highlight that supplements will be more effective in reducing LBW among women with poor nutritional status to start with. Thus, below-median MUAC and BSFT can be used as an indicator to screen women presenting for prenatal care for more rigorous efforts for supplementation to reduce LBW. MUAC and BSFT at delivery have been reported to be strongly correlated with MUAC and BSFT during early pregnancy ${ }^{(16)}$.

Inadequate prenatal care has been reported to be associated with LBW from many settings across the world like the USA, France, Finland, Brazil, Saudi Arabia, Bangladesh, Nepal and India ${ }^{(27-29)}$. Furthermore, it is well reported that provision of prenatal care is associated with improvement in $\mathrm{LBW}^{(30)}$. However, other studies have reported no association of no or low prenatal care with poor birth outcomes $^{(31)}$. Many indices are used to assess the adequacy of prenatal care, incorporating the date of the first visit, total number of visits and length of pregnancy. However, inconsistencies in the definition of adequacy have led to controversies about the effectiveness of the current model 
Table 2 Crude prevalence ratios and their $95 \%$ confidence interval for factors associated with low birth weight in Karachi, Pakistan, 2005-2006

\begin{tabular}{|c|c|c|c|c|c|c|}
\hline & \multirow[b]{2}{*}{ Total $n$} & \multicolumn{2}{|c|}{ Low birth weight } & \multirow[b]{2}{*}{ PR } & \multirow[b]{2}{*}{$95 \% \mathrm{Cl}$} & \multirow[b]{2}{*}{$P$} \\
\hline & & $n$ & $\%$ & & & \\
\hline \multicolumn{7}{|l|}{ Child gender } \\
\hline Female & 251 & 51 & 20 & $1 \cdot 19$ & $0 \cdot 84,1 \cdot 70$ & 0.316 \\
\hline Male & 289 & 49 & 17 & $1 \cdot 00$ & - & \\
\hline \multicolumn{7}{|l|}{ Parent characteristics } \\
\hline \multicolumn{7}{|l|}{ Mother's age at delivery (years) } \\
\hline$<20$ & 38 & 6 & 16 & $0 \cdot 80$ & $0.35,1 \cdot 83$ & 0.594 \\
\hline $21-30$ & 401 & 74 & 18 & 0.93 & $0 \cdot 60,1 \cdot 45$ & $0 \cdot 755$ \\
\hline$>30$ & 101 & 20 & 20 & $1 \cdot 00$ & - & \\
\hline \multicolumn{7}{|c|}{ Mother's education (years of schooling) } \\
\hline$<5$ & 177 & 33 & 19 & $1 \cdot 31$ & $0 \cdot 55,3 \cdot 11$ & 0.548 \\
\hline $6-12$ & 328 & 62 & 19 & $1 \cdot 32$ & $0.57,3.07$ & 0.515 \\
\hline$>12$ & 35 & 5 & 14 & $1 \cdot 00$ & - & \\
\hline \multicolumn{7}{|c|}{ Father's education (years of schooling) } \\
\hline$<5$ & 125 & 26 & 21 & $1 \cdot 54$ & $0 \cdot 79,3 \cdot 01$ & $0 \cdot 207$ \\
\hline $6-12$ & 341 & 64 & 19 & $1 \cdot 39$ & $0 \cdot 75,2 \cdot 57$ & $0 \cdot 297$ \\
\hline$>12$ & 74 & 10 & 14 & $1 \cdot 00$ & - & \\
\hline \multicolumn{7}{|l|}{ Wealth index ${ }^{*}$} \\
\hline Low & 64 & 13 & 20 & $1 \cdot 11$ & $0.62,1.98$ & 0.731 \\
\hline Medium & 307 & 56 & 18 & 0.99 & $0 \cdot 67,1 \cdot 48$ & 0.978 \\
\hline High & 169 & 31 & 18 & $1 \cdot 00$ & - & \\
\hline \multicolumn{7}{|l|}{ Monthly household income } \\
\hline Median and less ( $\leq$ Rs. 7000) & 289 & 51 & 18 & 0.90 & $0 \cdot 63,1 \cdot 29$ & 0.576 \\
\hline Above median (>Rs. 7000) & 251 & 49 & 20 & $1 \cdot 00$ & - & \\
\hline Mother's ethnicity $\dagger$ & & & & & & \\
\hline Sindhi & 26 & 5 & 19 & 0.96 & $0 \cdot 42,2 \cdot 16$ & 0.914 \\
\hline Punjabi & 73 & 12 & 16 & $0 \cdot 82$ & $0 \cdot 47,1.43$ & 0.477 \\
\hline Pakhtoon & 30 & 4 & 13 & $0 \cdot 66$ & $0 \cdot 26,1 \cdot 69$ & 0.389 \\
\hline Baloch & 43 & 5 & 12 & 0.58 & $0 \cdot 25,1.35$ & 0.206 \\
\hline Urdu (Mohajir) & 368 & 74 & 20 & $1 \cdot 00$ & - & \\
\hline Maternal nutrient intake and nutrit & & & & & & \\
\hline BMI & & & & & & \\
\hline Low $\left(<18.5 \mathrm{~kg} / \mathrm{m}^{2}\right)$ & 22 & 4 & 18 & $0 \cdot 86$ & $0 \cdot 34,2 \cdot 14$ & $0 \cdot 741$ \\
\hline Normal $\left(18.5-24.9 \mathrm{~kg} / \mathrm{m}^{2}\right)$ & 297 & 63 & 21 & $1 \cdot 00$ & - & \\
\hline High $\left(25 \cdot 0-29 \cdot 9 \mathrm{~kg} / \mathrm{m}^{2}\right)$ & 158 & 23 & 15 & 0.69 & $0.44,1.06$ & 0.091 \\
\hline Obese $\left(\geq 30 \cdot 0 \mathrm{~kg} / \mathrm{m}^{2}\right)$ & 63 & 10 & 16 & $0 \cdot 75$ & $0 \cdot 41,1 \cdot 38$ & 0.351 \\
\hline MUAC & & & & & & \\
\hline 1st \& 2nd quartiles $(\leq 28.9 \mathrm{~cm})$ & 270 & 61 & 23 & $1 \cdot 56$ & $1 \cdot 09,2 \cdot 25$ & 0.016 \\
\hline 3 rd \& 4th quartiles $(>28.9 \mathrm{~cm})$ & 270 & 39 & 14 & $1 \cdot 00$ & - & \\
\hline BSFT & & & & & & \\
\hline 1st \& 2nd quartiles $(\leq 9.0 \mathrm{~mm})$ & 272 & 61 & 22 & $1 \cdot 54$ & $1 \cdot 07,2 \cdot 22$ & 0.018 \\
\hline 3 rd \& 4th quartiles $(>9.0 \mathrm{~mm})$ & 268 & 39 & 15 & $1 \cdot 00$ & - & \\
\hline Daily Fe supplement intake during & & & & & & \\
\hline Non-users & 299 & 31 & 15 & $1 \cdot 34$ & $0.91,1.97$ & $0 \cdot 127$ \\
\hline Users & 241 & 69 & 20 & $1 \cdot 00$ & - & \\
\hline Daily total $\mathrm{Fe}$ intake during pregn & & & & & & \\
\hline 1st quartile $(<20.4 \mathrm{mg})$ & 134 & 24 & 18 & $1 \cdot 10$ & $0 \cdot 65,1 \cdot 86$ & 0.725 \\
\hline 2nd quartile (20.5-29.7 mg) & 135 & 30 & 22 & $1 \cdot 36$ & $0 \cdot 83,2 \cdot 24$ & $0 \cdot 220$ \\
\hline 3rd quartile $(29 \cdot 8-77 \cdot 28 \mathrm{mg})$ & 136 & 24 & 18 & $1 \cdot 08$ & $0 \cdot 64,1 \cdot 83$ & $0 \cdot 767$ \\
\hline 4th quartile $(>77 \cdot 28 \mathrm{mg})$ & 135 & 22 & 16 & $1 \cdot 00$ & - & \\
\hline Daily Ca supplement intake during & & & & & & \\
\hline Non-users & 202 & 69 & 18 & 1.03 & $0 \cdot 70.1 \cdot 51$ & 0.879 \\
\hline Users & 338 & 31 & 19 & $1 \cdot 00$ & - & \\
\hline Daily total $\mathrm{Ca}$ intake during pregn & & & & & & \\
\hline 1st quartile $(\leq 724.9 \mathrm{mg})$ & 135 & 28 & 21 & $1 \cdot 17$ & $0 \cdot 71,1 \cdot 90$ & 0.538 \\
\hline 2nd quartile $(725 \cdot 0-965.6 \mathrm{mg})$ & 135 & 22 & 16 & 0.92 & $0.54,1.55$ & 0.746 \\
\hline 3rd quartile $(965 \cdot 7-1181 \cdot 1 \mathrm{mg})$ & 135 & 26 & 19 & 1.08 & $0.66,1.79$ & 0.754 \\
\hline 4 th quartile $(>1181.1 \mathrm{mg})$ & 135 & 24 & 18 & $1 \cdot 00$ & - & \\
\hline Daily vitamin C supplement intake & & & & & & \\
\hline Non-users & 134 & 29 & 22 & $1 \cdot 24$ & $0 \cdot 84,1 \cdot 82$ & $0 \cdot 290$ \\
\hline Users & 406 & 71 & 17 & $1 \cdot 00$ & - & \\
\hline Daily total vitamin $C$ intake during & & & & & & \\
\hline 1st quartile $(\leq 297.9 \mathrm{mg})$ & 135 & 36 & 27 & $1 \cdot 80$ & $1 \cdot 10,2 \cdot 94$ & 0.019 \\
\hline 2nd quartile (298.0-662.3 mg) & 135 & 18 & 13 & 0.90 & $0 \cdot 50,1 \cdot 62$ & $0 \cdot 727$ \\
\hline 3rd quartile $(662.4-979.6 \mathrm{mg})$ & 135 & 26 & 19 & 1.30 & $0 \cdot 76,2 \cdot 21$ & 0.334 \\
\hline 4th quartile $(>979.6 \mathrm{mg})$ & 135 & 20 & 15 & $1 \cdot 00$ & - & \\
\hline
\end{tabular}




\begin{tabular}{|c|c|c|c|c|c|c|}
\hline & \multirow[b]{2}{*}{ Total $n$} & \multicolumn{2}{|c|}{ Low birth weight } & \multirow[b]{2}{*}{ PR } & \multirow[b]{2}{*}{$95 \% \mathrm{Cl}$} & \multirow[b]{2}{*}{$P$} \\
\hline & & $n$ & $\%$ & & & \\
\hline \multicolumn{7}{|l|}{ Environmental exposures } \\
\hline \multicolumn{7}{|l|}{ Location of house with respect to road } \\
\hline On the main road & 94 & 16 & 17 & $0 \cdot 66$ & $0 \cdot 39,1 \cdot 11$ & $0 \cdot 122$ \\
\hline In the street near road & 286 & 43 & 15 & 0.57 & $0 \cdot 40,0.86$ & 0.006 \\
\hline In the street far from road & 160 & 41 & 26 & 1.00 & - & \\
\hline \multicolumn{7}{|l|}{ Exposure to tobacco smoke at home or work } \\
\hline Yes & 144 & 32 & 22 & $1 \cdot 29$ & $0 \cdot 89,1 \cdot 88$ & $0 \cdot 177$ \\
\hline No & 396 & 68 & 17 & 1.00 & - & \\
\hline \multicolumn{7}{|c|}{ Lived during pregnancy in house where insecticide was used } \\
\hline Yes & 396 & 66 & 17 & $0 \cdot 71$ & $0.49,1 \cdot 02$ & 0.063 \\
\hline No & 144 & 34 & 24 & $1 \cdot 00$ & - & \\
\hline \multicolumn{7}{|l|}{ Lived during pregnancy in house where DDT was used } \\
\hline Yes & 253 & 39 & 15 & 0.73 & $0.50,1.04$ & 0.084 \\
\hline No & 287 & 61 & 21 & $1 \cdot 00$ & - & \\
\hline \multicolumn{7}{|l|}{ Mosquito coils were used during pregnancy } \\
\hline Yes & 241 & 46 & 19 & $1 \cdot 06$ & $0 \cdot 74,1 \cdot 51$ & $0 \cdot 760$ \\
\hline No & 299 & 54 & 18 & $1 \cdot 00$ & - & \\
\hline Type of kitchen & & & & & & \\
\hline Indoor kitchen with no partition & 71 & 10 & 14 & 0.47 & $0 \cdot 22,1 \cdot 01$ & 0.054 \\
\hline Indoor kitchen with partition & 320 & 57 & 18 & $0 \cdot 60$ & $0 \cdot 35,1 \cdot 04$ & 0.067 \\
\hline Enclosed kitchen outside house & 112 & 22 & 20 & 0.66 & $0 \cdot 36,1 \cdot 23$ & $0 \cdot 191$ \\
\hline Outdoor kitchen & 37 & 11 & 30 & $1 \cdot 00$ & - & \\
\hline Doing all household work during pregnancy & & & & & & \\
\hline Yes & 345 & 70 & 20 & $1 \cdot 32$ & $0 \cdot 89,1 \cdot 95$ & $0 \cdot 164$ \\
\hline No & 195 & 30 & 15 & $1 \cdot 00$ & - & \\
\hline Cooking frequency & & & & & & \\
\hline Same or more often than before & 374 & 78 & 21 & 1.57 & $1 \cdot 02,2 \cdot 43$ & 0.042 \\
\hline Less than before & 166 & 22 & 13 & $1 \cdot 00$ & - & \\
\hline Total hours of rest per day in third trimester of pregna & & & & & & \\
\hline 1st \& 2nd quartiles ( $\leq 6 \mathrm{~h})$ & 127 & 52 & 19 & 1.01 & $0 \cdot 71,1 \cdot 44$ & 0.940 \\
\hline 3 rd \& 4th quartiles $(>6 \mathrm{~h})$ & 413 & 48 & 18 & $1 \cdot 00$ & - & \\
\hline Maternal obstetric/pregnancy-related medical factors & & & & & & \\
\hline Parity & & & & & & \\
\hline 0 or $\geq 5$ births & 219 & 47 & 22 & $1 \cdot 62$ & $1 \cdot 03,2 \cdot 53$ & 0.030 \\
\hline $2-4$ births & 327 & 53 & 16 & $1 \cdot 00$ & - & \\
\hline Physician diagnosed anaemia during pregnancy & & & & & & \\
\hline Yes & 240 & 51 & 21 & $1 \cdot 30$ & $0.91,1 \cdot 85$ & $0 \cdot 145$ \\
\hline No & 300 & 49 & 16 & $1 \cdot 00$ & - & \\
\hline Number of prenatal visits & & & & & & \\
\hline$\leq 1$ & 41 & 13 & 32 & $1 \cdot 88$ & $1 \cdot 13,3 \cdot 12$ & 0.015 \\
\hline $2-3$ & 155 & 29 & 19 & $1 \cdot 11$ & $0 \cdot 74,1 \cdot 66$ & $0 \cdot 613$ \\
\hline$\geq 4$ & 344 & 58 & 17 & $1 \cdot 00$ & - & \\
\hline Timing of first prenatal visit & & & & & & \\
\hline$>28$ weeks or no visit & 135 & 31 & 23 & 1.96 & $0.99,3.91$ & 0.054 \\
\hline $17-28$ weeks & 328 & 60 & 18 & $1 \cdot 57$ & $0 \cdot 81,3 \cdot 01$ & $0 \cdot 180$ \\
\hline$\leq 16$ weeks & 77 & 9 & 12 & 1.00 & - & \\
\hline Adequacy of prenatal care utilization & & & & & & \\
\hline No or 1 visit or first visit between 25 and 38 weeks & 247 & 45 & 18 & $1 \cdot 53$ & $0 \cdot 76,3 \cdot 08$ & 0.238 \\
\hline 2 visits or first visit between 17 and 24 weeks & 226 & 47 & 21 & $1 \cdot 74$ & $0 \cdot 87,3 \cdot 50$ & $0 \cdot 119$ \\
\hline$\geq 3$ visits and first visit before 16 weeks & 67 & 8 & 12 & $1 \cdot 00$ & - & \\
\hline Feeling of depression & & & & & & \\
\hline Very much to extreme & 72 & 21 & 29 & $1 \cdot 66$ & $1 \cdot 10,2 \cdot 51$ & $0 \cdot 017$ \\
\hline Quite a bit to some, enough to bother me & 47 & 5 & 11 & $0 \cdot 61$ & $0 \cdot 26,1 \cdot 42$ & $0 \cdot 249$ \\
\hline Little to none & 421 & 74 & 18 & $1 \cdot 00$ & - & \\
\hline Perception about health status & & & & & & \\
\hline Poor & 136 & 39 & 29 & $2 \cdot 39$ & $1 \cdot 27,4 \cdot 50$ & 0.007 \\
\hline Fair & 286 & 44 & 15 & $1 \cdot 08$ & $0.59,1.98$ & 0.803 \\
\hline Good & 118 & 17 & 14 & 1.00 & - & \\
\hline History of trauma or injury & & & & & & \\
\hline Yes & 53 & 13 & 25 & $1 \cdot 37$ & $0 \cdot 83,2 \cdot 28$ & $0 \cdot 251$ \\
\hline No & 487 & 87 & 18 & $1 \cdot 00$ & - & \\
\hline Vaginal discharge during pregnancy & & & & & & \\
\hline Yes & 130 & 19 & 15 & $0 \cdot 74$ & $0 \cdot 47,1 \cdot 17$ & $0 \cdot 179$ \\
\hline No & 410 & 81 & 20 & $1 \cdot 00$ & - & \\
\hline High blood pressure & & & & & & \\
\hline Yes & 74 & 13 & 18 & 0.94 & $0 \cdot 55,1 \cdot 60$ & $0 \cdot 822$ \\
\hline No & 466 & 87 & 19 & $1 \cdot 00$ & - & \\
\hline
\end{tabular}


Table 2 Continued

\begin{tabular}{|c|c|c|c|c|c|c|}
\hline & \multirow[b]{2}{*}{ Total $n$} & \multicolumn{2}{|c|}{ Low birth weight } & \multirow[b]{2}{*}{ PR } & \multirow[b]{2}{*}{$95 \% \mathrm{Cl}$} & \multirow[b]{2}{*}{$P$} \\
\hline & & $n$ & $\%$ & & & \\
\hline \multicolumn{7}{|c|}{ Gestational diabetes } \\
\hline Yes & 29 & 6 & 21 & $1 \cdot 12$ & $0.54,2 \cdot 35$ & 0.754 \\
\hline No & 511 & 94 & 18 & $1 \cdot 00$ & - & \\
\hline \multicolumn{7}{|c|}{ Umbilical cord BLL ( $\mu \mathrm{g} / \mathrm{dl})$} \\
\hline$<10$ & 281 & 57 & 20 & $1 \cdot 00$ & - & \\
\hline$\geq 10$ & 259 & 43 & 17 & $0 \cdot 82$ & $0.57,1 \cdot 17$ & 0.273 \\
\hline
\end{tabular}

PR, prevalence ratio (computed using log binomial regression); MUAC, mid upper-arm circumference; BSFT, biceps skinfold thickness; DDT, dichlorodiphenyltrichloroethane; BLL, blood lead level.

*Wealth index was based on proportionate weighted sum of household assets, categorized on the basis of tertiles.

tThe Mohajirs are group of people who migrated from parts of India not included in Pakistan at the time of creation of Pakistan, and they mostly speak Urdu.

Table 3 Multivariable log binomial regression models for factors associated with low birth weight in Karachi, Pakistan, 2005-2006

\begin{tabular}{|c|c|c|c|c|c|c|}
\hline \multirow[b]{2}{*}{ Risk factor } & \multicolumn{3}{|c|}{ Model with MUAC* } & \multicolumn{3}{|c|}{ Model with BSFT† } \\
\hline & $\operatorname{adjPR}$ & $95 \% \mathrm{Cl}$ & $P$ & $\operatorname{adjPR}$ & $95 \% \mathrm{Cl}$ & $P$ \\
\hline \multicolumn{7}{|l|}{ Perceived health status } \\
\hline Good & 1.00 & - & & 1.00 & - & \\
\hline Fair & 0.99 & $0.59,1.65$ & 0.970 & 0.97 & $0.58,1.62$ & 0.910 \\
\hline Poor & 1.83 & $1.09,3.07$ & 0.021 & 1.90 & $1.14,3.16$ & 0.014 \\
\hline \multicolumn{7}{|l|}{ MUAC/BSFT and dietary vitamin C intake $(\mathrm{mg} / \mathrm{d}) \ddagger$} \\
\hline MUAC/BSFT $>$ median \& vitamin C > 208.7 & 1.00 & - & & 1.00 & - & \\
\hline MUAC/BSFT $\leq$ median \& vitamin C $>208.7$ & 10.80 & $1.46,79.76$ & 0.020 & 5.10 & $1.20,21.63$ & 0.027 \\
\hline MUAC/BSFT $>$ median \& vitamin $C \leq 208 \cdot 7$ & 10.67 & $1.50,76.02$ & 0.018 & 5.21 & $1.29,20.95$ & 0.020 \\
\hline MUAC/BSFT $\leq$ median \& vitamin $C \leq 208.7$ & 13.19 & $1.85,93.79$ & 0.010 & 6.78 & $1.70,27.09$ & 0.007 \\
\hline \multicolumn{7}{|l|}{ Number of prenatal visits } \\
\hline$\geq 4$ & 1.00 & - & & 1.00 & - & \\
\hline $2-3$ & 1.27 & $0.86,1.89$ & 0.233 & 1.29 & $0.87,1.92$ & 0.213 \\
\hline$\leq 1$ & 2.18 & $1.39,3.43$ & 0.001 & 2.10 & $1.32,3.32$ & 0.001 \\
\hline \multicolumn{7}{|l|}{ Parity } \\
\hline $1-4$ births & 1.00 & - & & 1.00 & - & \\
\hline 0 or $\geq 5$ births & 1.53 & $1.08,2.16$ & 0.016 & 1.55 & $1.09,2.19$ & 0.013 \\
\hline \multicolumn{7}{|l|}{ Umbilical cord BLL } \\
\hline Low $(<10 \mu \mathrm{g} / \mathrm{dl})$ & 1.00 & - & & 1.00 & - & \\
\hline High $(\geq 10 \mu \mathrm{g} / \mathrm{dl})$ & 0.86 & $0.61,1.21$ & 0.380 & 0.84 & $0.59,1.18$ & 0.316 \\
\hline
\end{tabular}

adjPR, adjusted prevalence ratio, MUAC, mid upper-arm circumference; BSFT, biceps skinfold thickness.

*Model with MUAC as measure of nutritional status.

tModel with BSFT as measure of nutritional status.

fInteraction of MUAC/BSFT and vitamin C intake. Median MUAC $=28.9 \mathrm{~cm}$; median BSFT $=9.0 \mathrm{~mm}$; vitamin $\mathrm{C}$ of $>208.7 \mathrm{mg}=4$ th quartile .

of prenatal care ${ }^{(32)}$. To address the issue of adequate number of visits, timing and content, many trials were conducted in developed and developing countries. A recent WHO-sponsored review of trials testing a new model with fewer number of visits and a goal-oriented approach found that LBW incidence was the same even after reduced number of visits, although at substantially reduced cost ${ }^{(33)}$. In our study, one or no prenatal visit was significantly associated with LBW in comparison with four or more visits. Another study in Pakistan also reported an association of low prenatal visits (less than three) with $\mathrm{LBW}^{(34)}$. Thus, in our setting improving access to prenatal care could reduce LBW further.

Poor self-rated health status is a determinant of adverse health outcomes and mortality ${ }^{(35)}$. It has been suggested that improvement or decline in self-rated health reflects primarily ongoing changes in the amount of distress or limitation associated with physical symptoms, mainly chronic ill health ${ }^{(36)}$. A previous study of the self-rated health status of women in Pakistan reported them to have poor overall self-reported health ${ }^{(37)}$. These findings are consistent with the findings of studies on South Asian immigrants in the $\mathrm{UK}^{(38)}$. Distress also leads to more negative health perceptions and negative health perception promotes distress ${ }^{(39)}$. Stress during pregnancy has been found to be associated with low social support ${ }^{(40)}$. Studies have reported an association of low or lack of social support with $\mathrm{LBW}^{(41)}$. In our study, poor self-rated health status was associated with LBW. Taken together with the previous findings that poor self-rated health reflects chronic ill health, pregnant women in our study are experiencing chronic ill health and lack of well-being and social support that is affecting their own health as well birth outcomes. Overall well-being and chronic ill health need further investigation in the context of pregnancy and birth outcomes in a developing country 
setting. There have been studies about stress and social support, but more work is needed to replicate our findings by directly measuring self-rated health status, its association with birth outcomes and its implications in the reduction of LBW.

Various studies from different parts of the world using maternal blood and bone $\mathrm{Pb}$ levels and umbilical cord BLL as a marker of prenatal $\mathrm{Pb}$ exposure have reported inconsistent results for an association between $\mathrm{Pb}$ and $\mathrm{LBW}^{(11-13)}$. Such inconsistencies in results may be due to different populations with different background risks, different biomarkers used for measuring $\mathrm{Pb}$ exposure, or differences in control for important covariates. Findings from the current study are consistent with many other studies from different parts of the world which did not find an association of $\mathrm{Pb}$ levels and $\mathrm{LBW}^{(13,42-44)}$.

Studies have also reported the association of outdoor air pollution, exposure to biomass fuel and ETS with $\mathrm{LBW}^{(6,8,9)}$. However, none of these factors was significant in our study.

\section{Limitations}

The major strengths of the present study include the large sample size and measurement and control for important confounders. An FFQ was employed for estimation of dietary intakes of $\mathrm{Ca}, \mathrm{Fe}$ and vitamin $\mathrm{C}$ that has been used previously but not formally validated. Many of the exposure measurement methods were based on selfreport with the possibility of imperfect recall and misclassification. However, since all procedures were standardized and performed consistently, only nondifferential misclassification is likely, which may have attenuated measures of effect. The study enrolled women who gave birth in study hospitals. In urban areas of Pakistan, a substantial proportion $(\sim 30 \%)$ of women deliver at home ${ }^{(45)}$. Hence, those delivering at hospital may be different from women delivering at home in their cultural beliefs, medical conditions forcing them to deliver in hospital, or may be more health-conscious. Therefore, caution should be used about the generalizability of these findings. Another potential limitation is the possibility of selection bias. However, selection bias is not likely in our case, because selection bias occurs when the comparison group (non-LBW infants) does not provide an estimate of the exposure distribution in the source population from which the LBW cases originate. The nonLBW infants originated from the same hospitals as the LBW infants, representing the same secondary bases of LBW, thus reducing the risk of selection bias.

\section{Conclusion}

In Pakistan, mothers with low intake of vitamin $\mathrm{C}$ during pregnancy and poor nutritional status were more likely to give birth to an LBW infant. These results highlight the importance of supplementation of vitamin $\mathrm{C}$, which will be more effective in reducing LBW among women with poor nutritional status, although there remains a need to evaluate the effectiveness of vitamin $\mathrm{C}$ in reducing LBW through randomized trials. There is also a need to evaluate and replicate our finding that women with MUAC or BSFT below the median can benefit more from supplements. Very few prenatal care visits also the increased risk for LBW; thus access to prenatal care services should be improved. Moreover, future work should examine the reasons for under-utilization of already available services, including quality of care and the population's perceptions about the usefulness of these services. Environmental factors including umbilical cord BLL were not significantly associated with LBW.

\section{Acknowledgements}

The present work was supported by International Training and Research in Environmental and Occupational Health grant \# 5D43TW05750 from the Fogarty International Centre at the National Institutes of Health, awarded to University of Alabama at Birmingham, AL, USA. We are indebted to hospital administrators and staff of the study hospitals for their support in the conduct of our study. We thank our field team for its contribution to data collection and the participants for their time. N.Z.J. conceived the idea, designed the study, conducted analyses and prepared and revised the manuscript. N.S. and E.D. contributed in design, analysis and preparation and revision of the manuscript. S.M., R.O.L., S.K. and E.K. contributed in analysis and write-up. All authors read and approved the final version of manuscript. We further declare that we have no conflicts of interest.

\section{References}

1. Wardlaw T, Blanc A, Zupan J \& Åhman E (2004) Low Birthweight: Country, Regional and Global Estimates. New York: UNICEF and WHO.

2. Hack M, Klein NK \& Taylor HG (1995) Long-term developmental outcomes of low birth weight infants. Future Child 5, 176-196.

3. Godfrey KM \& Barker DJ (2001) Fetal programming and adult health. Public Health Nutr 4, 611-624.

4. Karim E \& Mascie-Taylor CG (1997) The association between birthweight, sociodemographic variables and maternal anthropometry in an urban sample from Dhaka, Bangladesh. Ann Hum Biol 24, 387-401.

5. Lewis C, Suffet IH \& Ritz B (2006) Estimated effects of disinfection by-products on birth weight in a population served by a single water utility. Am J Epidemiol 163, 38-47.

6. Maroziene L \& Grazuleviciene R (2002) Maternal exposure to low-level air pollution and pregnancy outcomes: a population-based study. Environ Health 1, 6.

7. Mavalankar DV, Trivedi CC \& Gray RH (1994) Maternal weight, height and risk of poor pregnancy outcome in Ahmedabad, India. Indian Pediatr 31, 1205-1212.

8. Mishra V, Dai X, Smith KR \& Mika L (2004) Maternal exposure to biomass smoke and reduced birth weight in Zimbabwe. Ann Epidemiol 14, 740-747. 
9. Ahluwalia IB, GrummerStrawn L \& Scanlon KS (1997) Exposure to environmental tobacco smoke and birth outcome: increased effects on pregnant women aged 30 years or older. Am J Epidemiol 146, 42-47.

10. Han S, Pfizenmaier DH, Garcia E, Eguez ML, Ling M, Kemp FW \& Bogden JD (2000) Effects of lead exposure before pregnancy and dietary calcium during pregnancy on fetal development and lead accumulation. Environ Health Perspect 108, 527-531.

11. Gonzalez-Cossio T, Peterson KE, Sanin LH, Fishbein E, Palazuelos E, Aro A, Hernández-Avila M \& Hu H (1997) Decrease in birth weight in relation to maternal bone-lead burden. Pediatrics 100, 856-862.

12. Awasthi S, Awasthi R \& Srivastav RC (2002) Maternal blood lead level and outcomes of pregnancy in Lucknow, North India. Indian Pediatr 39, 855-860.

13. Factor-Litvak P, Graziano JH, Kline JK et al. (1991) A prospective study of birthweight and length of gestation in a population surrounding a lead smelter in Kosovo, Yugoslavia. Int J Epidemiol 20, 722-728.

14. Kramer MS (2003) The epidemiology of adverse pregnancy outcomes: an overview. J Nutr 133, 1592S-1596S.

15. Iqbal R, Rafique G, Badruddin S, Qureshi R, Cue R \& Gray-Donald K (2007) Increased body fat percentage and physical inactivity are independent predictors of gestational diabetes mellitus in South Asian women. Eur J Clin Nutr 61, 736-742.

16. Taggart NR, Holliday RM, Billewicz WZ, Hytten FE \& Thomson AM (1967) Changes in skinfolds during pregnancy. Br J Nutr 21, 439-451.

17. Rahbar MH, White F, Agboatwalla M, Hozhabri S \& Luby S (2002) Factors associated with elevated blood lead concentrations in children in Karachi, Pakistan. Bull World Health Organ 80, 769-775.

18. Ernhart CB (1992) A critical review of low-level prenatal lead exposure in the human: 1 . Effects on the fetus and newborn. Reprod Toxicol 6, 9-19.

19. Ricalde AE, Velasquez-Melendez G, Tanaka AC \& de Siqueira AA (1998) Mid-upper arm circumference in pregnant women and its relation to birth weight. Rev Saude Publica 32, 112-117.

20. Ogbonna C, Woelk GB, Ning Y, Mudzamiri S, Mahomed K \& Williams MA (2007) Maternal mid-arm circumference and other anthropometric measures of adiposity in relation to infant birth size among Zimbabwean women. Acta Obstet Gynecol Scand 86, 26-32.

21. Bisai S, Mahalanabis D, Sen A, Bose K \& Datta N (2007) Maternal early second trimester pregnancy weight in relation to birth outcome among Bengalee Hindus of Kolkata, India. Ann Hum Biol 34, 91-101.

22. Rao S, Yajnik CS, Kanade A et al. (2001) Intake of micronutrient-rich foods in rural Indian mothers is associated with the size of their babies at birth: Pune Maternal Nutrition Study. J Nutr 131, 1217-1224.

23. Mathews F, Yudkin P \& Neil A (1999) Influence of maternal nutrition on outcome of pregnancy: prospective cohort study. BMJ 319, 339-343.

24. Lee BE, Hong YC, Lee KH, Kim YJ, Kim WK, Chang NS, Park EA, Park HS \& Hann HJ (2004) Influence of maternal serum levels of vitamins $\mathrm{C}$ and $\mathrm{E}$ during the second trimester on birth weight and length. Eur J Clin Nutr 58, 1365-1371.

25. Wang Y \& Walsh SW (2001) Increased superoxide generation is associated with decreased superoxide dismutase activity and mRNA expression in placental trophoblast cells in pre-eclampsia. Placenta 22, 206-212.

26. Scholl TO \& Stein TP (2001) Oxidant damage to DNA and pregnancy outcome. J Matern Fetal Med 10, 182-185.
27. Abdelmoneim I (2004) A study of determinants of low birth weight in Abha, Saudi Arabia. Afr J Med Med Sci 33, 145-148.

28. Blondel B \& Marshall B (1998) Poor antenatal care in 20 French districts: risk factors and pregnancy outcome. J Epidemiol Community Health 52, 501-506.

29. Raatikainen K, Heiskanen N \& Heinonen S (2007) Underattending free antenatal care is associated with adverse pregnancy outcomes. BMC Public Health 7, 268.

30. Barros H, Tavares M \& Rodrigues T (1996) Role of prenatal care in preterm birth and low birthweight in Portugal. J Public Health Med 18, 321-328.

31. Fujita N, Matsui M, Srey S, Po CS, Uong S \& Koum K (2005) Antenatal care in the capital city of Cambodia: current situation and impact on obstetric outcome. J Obstet Gynaecol Res 31, 133-139.

32. Misra DP \& Guyer B (1998) Benefits and limitations of prenatal care: from counting visits to measuring content. JAMA 279, 1661-1662.

33. Carroli G, Villar J, Piaggio G, Khan-Neelofur D, Gulmezoglu M, Mugford M, Lumbiganon P, Farnot U \& Bersgjø P; WHO Antenatal Care Trial Research Group (2001) WHO systematic review of randomised controlled trials of routine antenatal care. Lancet 357, 1565-1570.

34. Tasnim N, Mahmud G \& Arif MS (2005) Impact of reduced prenatal visit frequency on obstetric outcome in low-risk mothers. J Coll Physicians Surg Pak 15, 26-29.

35. Idler EL \& Benyamini Y (1997) Self-rated health and mortality: a review of twenty-seven community studies. $J$ Health Soc Behav 38, 21-37.

36. Goldstein MS, Siegel JM \& Boyer R (1984) Predicting changes in perceived health status. Am J Public Health $\mathbf{7 4}$, 611-614.

37. Ahmad K, Jafar TH \& Chaturvedi N (2005) Self-rated health in Pakistan: results of a national health survey. BMC Public Health 5, 51.

38. Chandola T (2001) Ethnic and class differences in health in relation to British South Asians: using the new National Statistics Socio-Economic Classification. Soc Sci Med 52, $1285-1296$.

39. Farmer MM \& Ferraro KF (1997) Distress and perceived health: mechanisms of health decline. J Health Soc Behav 38, 298-311.

40. Dejin-Karlsson E, Hanson BS, Ostergren PO, Lindgren A, Sjoberg NO \& Marsal K (2000) Association of a lack of psychosocial resources and the risk of giving birth to small for gestational age infants: a stress hypothesis. BJOG 107, 89-100.

41. Elsenbruch S, Benson S, Rucke M, Rose M, Dudenhausen J, Pincus-Knackstedt MK, Klapp BF \& Arck PC (2007) Social support during pregnancy: effects on maternal depressive symptoms, smoking and pregnancy outcome. Hum Reprod 22, 869-877.

42. Ernhart CB, Wolf AW, Kennard MJ, Erhard P, Filipovich HF \& Sokol RJ (1986) Intrauterine exposure to low levels of lead: the status of the neonate. Arch Environ Health 41, 287-291.

43. Sowers M, Jannausch M, Scholl T, Li W, Kemp FW \& Bogden JD (2002) Blood lead concentrations and pregnancy outcomes. Arch Environ Health 57, 489-495.

44. Andrews KW, Savitz DA \& Hertz-Picciotto I (1994) Prenatal lead exposure in relation to gestational age and birth weight: a review of epidemiologic studies. Am J Ind Med 26, 13-32.

45. National Institute of Population Studies \& Macro International (2007) Pakistan Demographic and Health Survey 2006-07-Preliminary Report. Islamabad: NIPS. 